\title{
STRUCTURE OF FREE GAS OUTFLOWS FROM BLOWING NOZZLES OF THERMAL AGGREGATES
}

\author{
Ladislav KOVÁŘ, Pavel NOVÁK \\ VSB - Technical University of Ostrava, Faculty of Mechanical Engineering, Ostrava, Czech Republic, EU, \\ ladislav.kovar@vsb.cz, pavel.novak.st1@vsb.cz
}

https://doi.org/10.37904/metal.2019.788

\begin{abstract}
Design and construction issues of blowing systems, lances and nozzles for high-temperature reactors is a hot issue, which addresses not only metallurgy but also other industrial sectors. In general, the problems of design and construction solutions are mainly oriented on issues of reducing the consumption of materials and energy, which ultimately affect the investment and operating costs of the aggregates. Among the most watched indicators can be included, for example, a reduction of the blowing media consumption while reducing the energy intensity of the technical production process and increasing the degree of its use. According to the nature of the distribution in individual determinating quantities, we can, when e.g. considering a metallurgical heat aggregate, determine the dynamic effect of a outlet flow on the working space (a bath), a change in the blown gas concentration and the best position of the lance with a view to increase its lifespan while reducing wear on the lining of the respective heat aggregate. Using the outlet flows from the lances we can analyse the parameters significantly affecting the design of the lance and nozzles intended for the given purpose. These are, for example, the interaction of outlet flows in multi-nozzle lances, the length of the supersonic flow core, the angle of outlet flows extension depending on the geometry of the nozzles, the effect of the nozzles shape on the outlet flow parameters and shaping of nozzles. Knowledge of the basic properties of the outlet flow field from the lances and nozzles helps designers and engineers to meet demanding requirements for the blowing systems. This paper presents the distribution and structure of free streams from lances including their selected characteristics.
\end{abstract}

Keywords: Steelmaking, lance, lance outflows, gas blowing, lance outflows parameters

\section{INTRODUCTION}

The following text will generally describe the distribution and basic properties of the flow field from a lance. This implies the outlet flow flowing into a calm and stationary, or eventually, into a moving gaseous or liquid environment, both without chemically interacting with the flow, and taking this effect into consideration. These basic characteristics of the flow affect, for example, the lance distance from the liquid bath or the general technological function of the lance in a given reactor. According to the flow speed value in the nozzle outlet section, we can divide the flow streams into subsonic or sub-critical $M_{v}<1$, sonic or critical in which is $M_{v}=1$ and supersonic or supercritical with value $M_{v}>1$, where $M_{v}$ is the value of the Mach number in the nozzle outlet section [1]. From that classification, the difference between the individual outlet flows is obvious, which is given by the speed value in the output section and the resulting difference in the structure of the flow field behind the nozzle mouth. Below is a description of the structure and properties of the subsonic and supersonic flow, selected flow characteristics and a description of the structure of flows from multi-nozzles lances.

\section{DISTRIBUTION AND ANALYSIS OF FREE OUTLET FLOWS}

Depending on the environment to which the stream flows, we can divide the outlet flows into:

1) Free outlet flow - Environment is calm, immovable, does not interact with the environment (e.g. chemical etc.), 
2) Free outlet flow - Environment is calm, immovable, there is a chemical interaction,

3) Outlet stream flows into the moving environment (parallel flow or counterflow, or eventually with any flow direction) and there is no possible chemical interaction,

4) Outlet stream flows into the gaseous or liquid environment,

In addition, we can divide the outlet flows, with regard to the practical applications of blowing gases into metallurgical reactors, considering the previous classification into:

5) Outlet flows from the stationary lance above the bath (e.g. LD process),

6) Outlet flows from the lance moving above the bath,

7) Pulsing outlet flow in a combination of 1,2 either with the full or partial pulses of gas outflow parameters from the lance.

\section{THE STRUCTURE OF AXIALLY SYMMETRICAL FREE SUBSONIC FLOW OF THE GAS}

As shown in the schematic representation (Figure 1), in the case of a free subsonic, axis-symmetric flow, the axial speed of the flow $v_{o s}$ is constant in the flow kernel area and equals the output speed from the nozzle, that is $v_{o s}=v_{v}$. In the remaining part of the flow cross-section, the flow speed decreases due to the mixing effect. The flow structure is mainly influenced by the turbulence in and out of the nozzle itself [2]. If the blowing agent flows into a gaseous environment of a different composition than the outlet flow, in the outlet flow there changes temperature, pressure, speed, specific weight and the concentration, which corresponds to the operating conditions in the reactor. The effect of the flow acting on a bath melt is relatively low with respect to the outlet flow characteristics and it depends on the distance of the lance from the bath $h_{\varnothing}$.

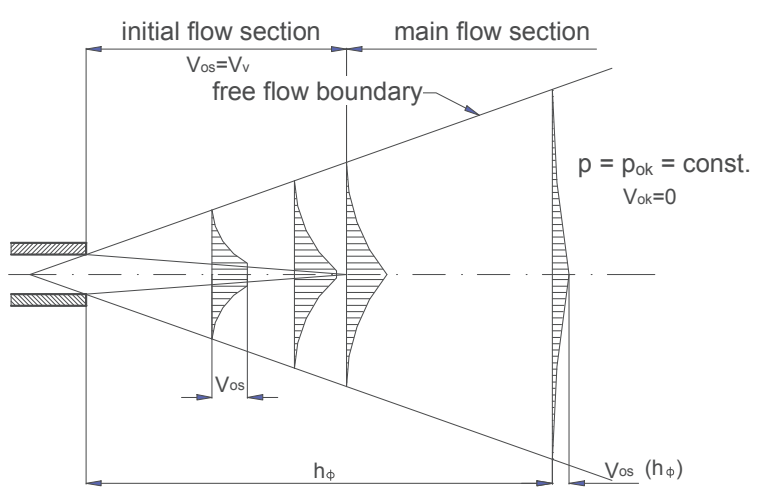

Figure 1 Schematic representation of the free subsonic flow flowing from the nozzle to the calm surrounding environment

\section{THE STRUCTURE OF FREE SUPERSONIC FLOW FROM THE NOZZLE}

The advantage of the supersonic free flow outflow speed field is the high value of the flow momentum and, depending on the position of the lance above the metal surface, also the concentration of the blown gas (it may be oxygen in steelmaking aggregates), which implies the greatest effect of the flow on the intensity of mixing the melt in the reactor.

In order to describe the supersonic free flow at the time of the steady state of the flow (Figure 2), the individual areas of the flow can be defined according to [3]:

a) Starting section - pressure waves in this section have the highest intensity;

b) First transition section of the stream - for this part the transverse distribution of the flow velocity resembling an upper-case letter " $\mathrm{M}$ " is typical; 
c) Second transition section of the stream - bounds the area between the maximum and constant speed areas;

d) The main stream - continues to a distance where the flow speed is equal to zero (the pressure of the blown agent expands to the ambient pressure value).

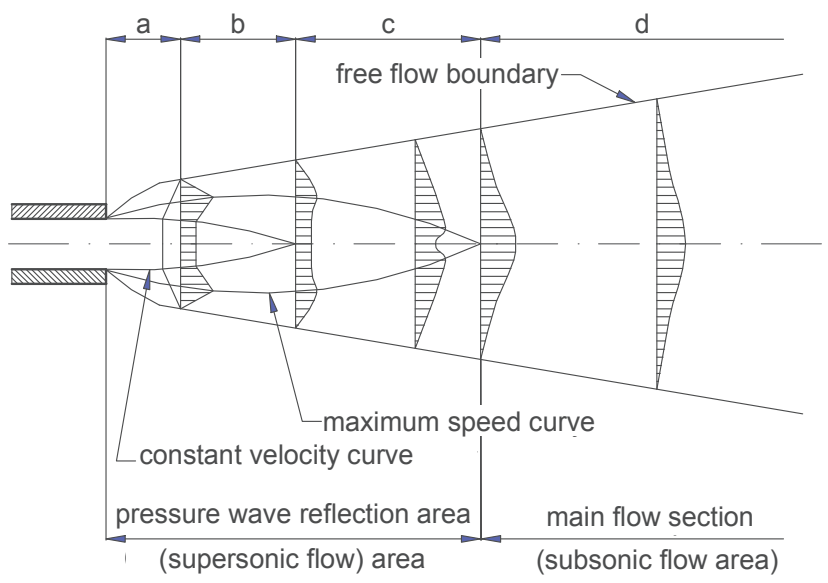

Figure 2 Diagram of the flow field structure of an axially symmetrical free supersonic flow with a radial flow rate distribution

In $a, b, c$ areas, there is a reflection of the pressure waves. The flow current field, therefore, has a wave structure (area a, b, c where pKpok consists of expansion and compression pressure waves). There is a discontinuous change in all current quantities and thus losses. When calculating and designing the shape of nozzles, it is necessary to adhere to the so-called calculated (designed) media flow mode, ensuring minimal flow losses and a low noise level.

The position (distance) of the lance above the melt $h_{\phi}$ is a function of the blown agent concentration from the lance, flow impulse values, the reaction zone dimension, melt spray degree and melt mixing intensity (Figure 3).

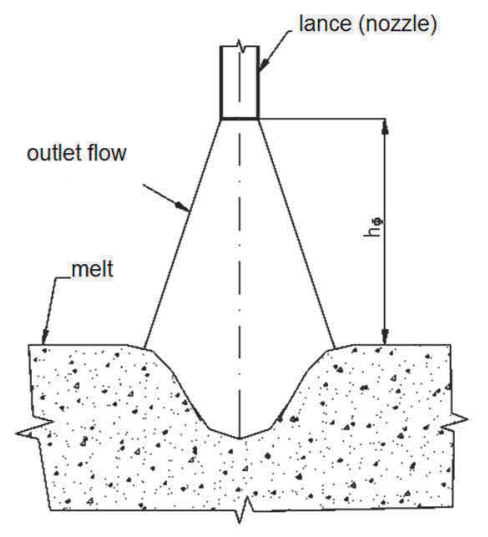

Figure 3 Schematic illustration of the lance position above the melt and the effect of the outlet flow on the melt

Practically, to determine the position of the lance above the melt, the dimensionless values $\mathrm{j} / \mathrm{d}_{\mathrm{kr}}$ can be used, where $\mathrm{l}_{\mathrm{j}}$ represents the length of the supersonic core of the outlet flow and $\mathrm{d}_{\mathrm{kr}}$ the critical diameter of a nozzle, on the total pressure $p_{0}$ in front of the nozzle. Dependency progress $l_{j} / d_{k r}=f\left(p_{0}\right)$ is shown in the (Figure 4). In other publications, we can find a mathematical or graphical illustration of the supersonic core length of the 
outlet flow dependency on other variables, for example, on the Mach number value in the output section of the lance [4].

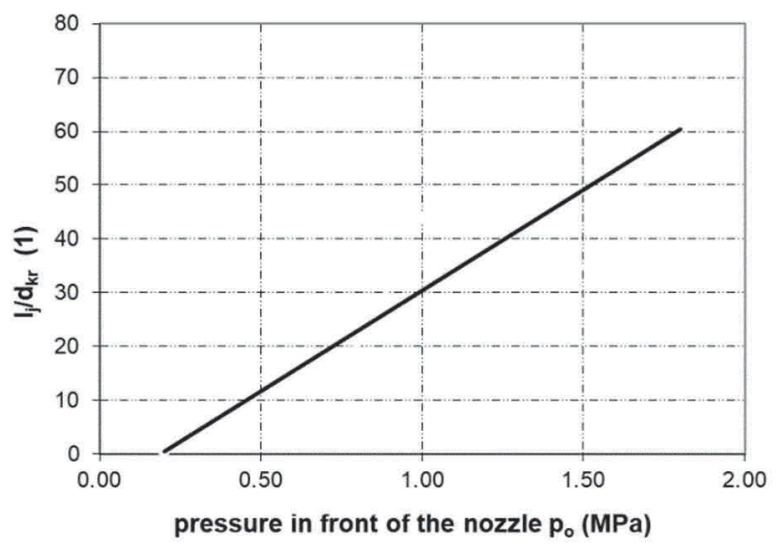

Figure 4 Course $\mathrm{l}_{\mathrm{j}} / \mathrm{d}_{\mathrm{kr}}=\mathrm{f}\left(\mathrm{p}_{0}\right)$

In the case of steel production, in some shops, the distance of the lance from the melt was introduced as a reference distance of a length equal to the supersonic core of the flow.

To determine the length of the supersonic core for the outlet flow, e.g. the following expression can be used [5]

$$
\frac{p_{v}}{p_{o k}}=\frac{l_{j}}{D} \cdot \exp ^{-0.11 \gamma M_{v}^{2}}
$$

$$
\begin{aligned}
& M_{v} \text { - fully expanded jet Mach number (1) } \\
& Y \text { - specific heat ratio of the gas (1) } \\
& p_{o k} \text { - ambient pressure (MPa) } \\
& D \text { - the jet diameter (m) } \\
& l_{j} \text { - supersonic core length }(\mathrm{m}) \\
& p_{v} \text { - lance exit pressure (MPa) }
\end{aligned}
$$

Other expressions, which can be used to determine the length of the supersonic core of the outflow are given below

$$
\begin{aligned}
& l_{j}=6 \cdot 2 \cdot \frac{d_{v}}{\sqrt{n}} \cdot M_{v}^{1.572 \pm 0.281} \\
& l_{j}=\frac{d \cdot(0.96 \cdot v+0.29 \cdot c)}{0.14 \cdot c}
\end{aligned}
$$

$$
\begin{aligned}
& n \text { - number of jets in the lance head (1) } \\
& d \text { - outlet diameter of the lance }(\mathrm{m}) \\
& M_{v} \text { - Mach number in the output section (1) } \\
& c \text { - sound speed }\left(\mathrm{m}_{\mathrm{s}} \mathrm{s}^{-1}\right) \\
& v \text { - output speed of the current }\left(\mathrm{m} \cdot \mathrm{s}^{-1}\right)
\end{aligned}
$$

The relationship between $h_{\phi}$ and $l_{j}$ depends on the charge processing technology in the reactor. In this context, two types of blowing are recognized, so-called "hard blowing" and "soft blowing". In the first case, we achieve 
a higher intensity of the ongoing reactions of the outlet flow and melt, which may be accompanied by higher slopping. The value of $h_{\phi}$, in this case, is close to the value of $l_{j}$. In the latter case, it is the so-called slag operation, when it particularly comes to the creation of a sufficient amount of slag. The value of $h_{\phi}$ is higher than in the first case, and it is several times the value of $\mathrm{l}_{\mathrm{j}}$.

\section{FREE-FLOW STRUCTURE FROM MULTI-NOZZLE LANCES}

In practice, multi-hole (multi-nozzle) lance heads are used very often. The multi-hole steelmaking lances are designed so that several nozzles are placed in one head. Most often there are three to a maximum of nine nozzles. The aim of these design solutions is to evenly distribute blowing and enlarge the reaction area affected by the blowing gas [6]. The design of each nozzle corresponds to the given flow of the blowing gas and to the environmental parameters in front of the lance head.
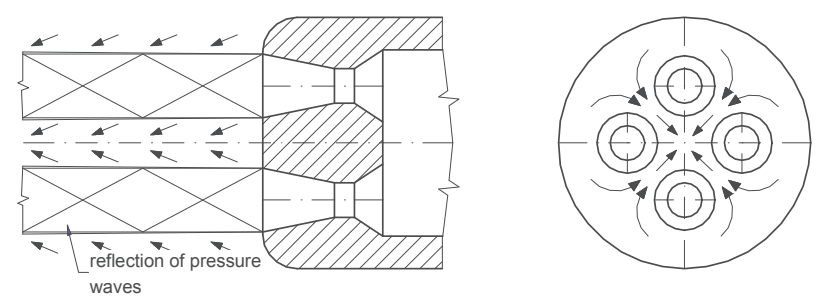

a) ejection mode
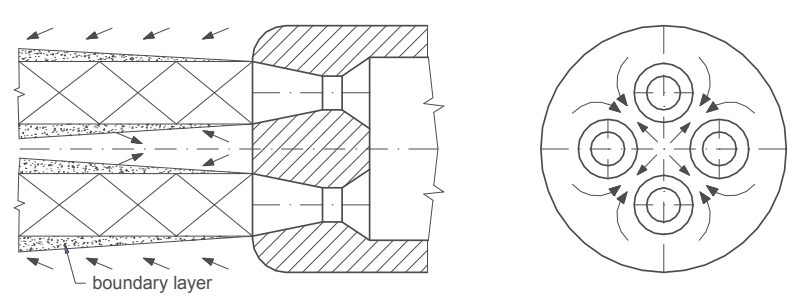

b) transition mode
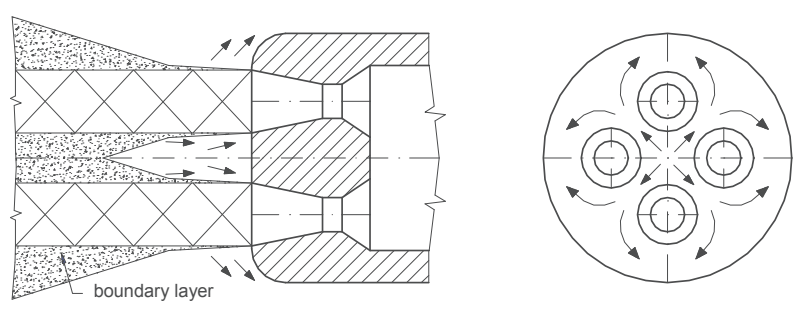

c) reverse flow mode

Figure 5 Flow structure behind lance front

A factor the flow field depends on is behind the mouth of the nozzle, which outside the designed flow forms the reflections of pressure waves. When the gas passes through these waves, there is a discontinuous anisoentropic change in the outlet flow. Depending on the shape of the nozzles, on the mass flow of gas, the environment parameters in front of the nozzle, the angle between the nozzles and even on the angle of the nozzle axis to the steelmaking lance longitudinal axis, the following cases of flow can occur in the space between the nozzles of each jet: an ejection mode, a transition mode and a reverse flow mode (Figure 5). In the ejection mode, there is no interaction of the individual outlet flows in the main section of the outlet flows, and under pressure between flows, the surrounding environment is injected. With the pressure rise in front of the lance head or there is a reduction of the ambient pressure in front of the nozzle or the angle between the 
nozzles, a transition mode of flow occurs first, changing into a reverse flow mode. There may be such a case when the pressure in the frontal part does not depend on the environmental pressure, and the mode of the area between the streams and the front part of lance head is closed.

\section{CONCLUSION}

The design of blowing systems and lances for high-temperature reactors is still a hot topic, concerning not only metal production and processing equipment, but it is related to many other industrial sectors. This paper provides a basic description of free outflow streams from nozzles with respect to the environment, into which this stream flows. Furthermore, there is a description of the structure and properties of the subsonic and supersonic flow. In the case of a supersonic flow, the selected characteristics of the flow are described that affect its technological properties in its application in thermal reactors. The final part is devoted to describing the structure of flows flowing from multi-nozzle lances, and to the mechanisms of their interactions.

The design and structure of the lance and nozzle, or rather of the whole blowing system, is influenced by a number of requirements. The final quality of the designed system can be assessed according to its operational utility parameters, among which we can include the consumption of a blowing agent, the degree of their use, wear of the blower nozzles and other areas. These utility parameters are mainly influenced by the properties and parameters of the flowing agent, which we can influence by the design of the nozzle. Knowledge of the basic characteristics of the flow from the nozzles helps designers meet the demanding requirements for these blowing systems. These basic features include the distribution of individual determination values, which influences the dynamic effect of the flow on the melt and from which the best position of the lance above the liquid melt surface can be deduced. This position is in many cases derived from the length of the supersonic core of the outlet flow. A qualitative picture of free outlet flows can be obtained, in addition to analytical calculation and computer simulations, for example using flow visualization methods. By analyzing visualized images, the characteristic cross-sections can be defined, where it is possible to determine the distribution of individual assessment quantities by quantitative contact measurements.

\section{REFERENCES}

[1] DEJČ, M.E. Technical gas dynamics. SNTL Praha, 1967, 660p.

[2] VIJAYAKUMARAN, H., LEMMA, T. A. Simulation of swirling wet steam flow through a supersonic nozzle. In 6th INTERNATIONAL CONFERENCE ON PRODUCTION, ENERGY AND RELIABILITY 2018: World Engineering Science \& Technology Congress (ESTCON) DOI: 10.1063/1.5075558. [viewed 2019-04-01]. Available from: https://www.researchgate.net/publication/328936855 Simulation of swirling wet steam flow through a supers onic nozzle

[3] MIKOLAJEK, J.: Steelworks equipment I. Textbook VŠB Ostrava, 1985. 206p.

[4] SMITH, G.C. Multiple jet oxygen lances - Theoretical analysis and correlation with practice. in JOM: the journal of the Minerals, [online] Metals \& Materials Society 18(7):846-851 · July 1966. [viewed 2019-04-24]. Available from: https://doi.org/10.1007/BF03378475

[5] PERUMAL K. A., RATHAKRISHNAN E. Corrugated right-angled triangular tabs for supersonic jet control, [online] in Proceedings of the Institution of Mechanical Engineers Part G Journal of Aerospace Engineering · September 2015. [viewed 2019-04-14]. Available from: https://www.researchgate.net/publication/282925269

[6] Oxygen blowing lance and lance tips in converter steelmaking [online] Ispadguru [viewed 2019-04-24]. Available from: http://ispatguru.com/oxygen-blowing-lance-and-lance-tips-in-converter-steel-making/ 